\title{
The Association Between Cancer Incidence, HIV Prevalence, and Gross Domestic Product in Uganda
}

\author{
Kelvin Roland Mubiru ${ }^{1}$, Hellen Namawejje ${ }^{1, ~}$, Leonard Atuhaire ${ }^{2}$ \\ ${ }^{1}$ Department of Statistical Methods and Actuarial Science, Makerere University, Kampala, Uganda \\ ${ }^{2}$ Department of Planning and Applied Statistics, Makerere University, Kampala, Uganda
}

\section{Email address:}

mubirukr@gmail.com(K. R. Mubiru), hnamawejje2@bams.mak.ac.ug(H. Namawejje), hnamawejje@gmail.com (H. Namawejje), leonardatuhaire $a$ gmail.com (L. Atuhaire)

${ }^{*}$ Corresponding author

\section{To cite this article:}

Kelvin Roland Mubiru, Hellen Namawejje, Leonard Atuhaire. The Association Between Cancer Incidence, HIV Prevalence, and Gross Domestic Product in Uganda. Science Journal of Applied Mathematics and Statistics. Vol. 8, No. 1, 2020, pp. 19-26.

doi: 10.11648/j.sjams.20200801.13

Received: January 25, 2020; Accepted: February 10, 2020; Published: February 14, 2020

\begin{abstract}
This research examines the association of cancer incidence, HIV prevalence and gross domestic product in Uganda. The study utilised secondary data were Cancer data was obtained from the Kampala Cancer Registry, Uganda. Gross domestic product data from IMF's World Economic Outlook and AIDS data from UNAIDS 2017 report. Multivariate time series analysis method was used covering a period from 1993 -2014. The research findings indicate that the Non-AIDS defining cancers, that is, stomach $(\mathrm{p}=0.000)$, eye $(\mathrm{p}=0.000)$, liver $(\mathrm{p}=0.000)$ and prostate $(\mathrm{p}=0.000)$ had a long run positive significant relationship with HIV prevalence while colon $(\mathrm{p}=0.002)$, lung $(\mathrm{p}=0.00)$ and breast $(\mathrm{p}=0.004)$ had a negative significant relationship with HIV prevalence. Also breast $(\mathrm{p}=0.00)$ and prostate $(\mathrm{p}=0.001)$ had a positive significant relationship with Gross domestic product while cancer of the lung $(\mathrm{p}=0.000)$ had a negative significant relationship with gross domestic product in Uganda. AIDS defining cancers such as Non-Hodgkin cancer $(\mathrm{p}=0.001)$ had a long run positive significant relationship with HIV prevalence while cervical $(\mathrm{p}=0.000)$ had a negative significant relationship with HIV prevalence. Cervical cancer $(\mathrm{p}=0.014)$ had a positive significant relationship with Gross domestic product in Uganda. The study recommends government to enhance policies that reduce HIV since it was observed that HIV had a significant relationship with cancer.
\end{abstract}

Keywords: Cancer Incidence, GDP, HIV Prevalence, Time Series Analysis

\section{Introduction}

According to the American Cancer Society and National cancer institute [1] Cancer is an abnormal growth of cells which tend to grow in an uncontrolled way and can spread to other parts of the body. In Sub-Saharan Africa (SSA), [3] states that little is known about cancer among people living with immunodeficiency virus (HIV) despite the fact that $70 \%$ of global human immunodeficiency virus (HIV) burden is concentrated $[2,3]$ with three AIDS-defining malignancies, Kaposi Sarcoma, cervical cancer and non-Hodgkin lymphoma (NHL) being among the top 10 cancers [4]

The increasing trends of cancer burden especially in SSA has also had a major impact on the different national economic development [8]. Other factors have been associated to the growing and aging population and economic factors have also played a vital role [2]. Various researchers $[2,3,5]$ have shown that Gross domestic product has been widely measured when comparing economic development of a country from previous years [7]. Prostate cancer is common cancer for men worldwide as the case for breast cancer for women. The study by $[6,8]$ shows that incidence rate of prostate cancer was greater in countries with higher GDP Furthermore in Europe a couple of studies have concluded that HIV infected persons have a higher risk for certain types of cancers than the general population [5].

Cancer is an emerging public health problem in Africa because about 715,000 new cancer cases and 542,000 cancer deaths occurred in 2008 on the continent, with these numbers expected to double in the next 20 years. In Uganda particularly there has been an overall increase in the risk of 
cancer during the year 1991-2010 in both sexes, with incidence rates of major cancers such as breast and prostate showing particularly marked increases that is, 3.7\% and 5.2\% annually, respectively [9].

Several studies have described major declines in the occurrence of non-Hodgkin lymphoma and other cancers such as Kaposi's sarcoma and cervical cancer among HIVinfected persons and have attributed these major declines to the introduction of HAART. Furthermore HIV-infected persons, including those who have developed AIDS, have higher risk for some non- AIDS-defining cancers, such as cancers of the stomach, liver and anus, and Hodgkin lymphoma [10]. While these cancers are an important source of morbidity, little has been researched about them in Uganda. In addition, few reports of cancer incidence have thoroughly investigated cancer incidence among adults ages 15-49 after the introduction of HAART.

With little information available regarding how HIV prevalence and incidence of cancer affect gross domestic product, this study examines the association between HIV prevalence, cancer incidence and gross domestic product in Uganda by (i) establishing the relationship between incidence of non-AIDS defining cancers and prevalence of HIV (ii) determining the relationship between incidence of non-AIDS defining cancers and GDP as well as (iii) analyzing the relationship between incidence of AIDS defining cancers and GDP in Uganda.

\section{Methodology}

\subsection{Source of Data}

Cancer data was obtained from the Kampala Cancer Registry, Department of Pathology, College of Health Sciences, Makerere University. Data collected was in terms of cases of cancer recorded from 1993-2014.

GDP data was obtained from GDP data by country from IMF's World Economic Outlook [11]. The World Economic Outlook (WEO) database contains selected macroeconomic data series from the statistical appendix of the World Economic Outlook report, which presents the IMF projections of economic developments at the global level, in major country groups and in many individual countries. The WEO is released in April and September/October each year. GDP data collected was in terms of US dollars (billions) from 1993-2014. AIDS data was obtained from report on the global AIDS epidemic UNAIDS/WHO 2017 [14].

\subsection{Variables and Their Measurements}

The variables are cancer incidence, estimates of prevalence of HIV measured in terms of percentages, gross domestic product (GDP) which will be measured in terms of US dollars and time measured in terms of years. The 10 selected cancers are divided into two groups, the first one are the AIDS defining cancer that is cervical cancer and nonHodgkin lymphoma [NHL], the second group is the nonAIDS-related cancers that is breast, prostate, stomach, eye, colon, Hodgkin Lymphoma, Lung, liver.

\subsection{Data Analysis}

The study was retrospective studying 10 selected cancers, prevalence of AIDS and gross domestic product from 19932014. Data was obtained and imported in STATA 13.0 for analysis which involved Multivariate time series analysis. A model for each of the 10 cancer types was ran to find out the association of Cancer incidence, HIV prevalence and GDP in Uganda. Each variable was endogenous and was a function of its lagged value and the lagged values of other variables.

\subsection{Testing for Stationarity and Co-integration}

The Variables were tested for stationarity using the Augmented Dickey-Fuller test. The null hypothesis was that variables are non-stationary against the alternative that variables are stationary. When the absolute test statistic is greater than the $5 \%$ critical value, we rejected the null hypothesis otherwise we failed to reject the null hypothesis [12, 13]. The three variables were tested for co-integration using the Johansen co-integration test and in case of no cointegration a Vector Autoregressive model (VAR) was used otherwise in the presence of co-integration a vector error correction model (VECM) was used to find out the association of cancer incidence, HIV prevalence and GDP [12].

\subsection{Optimal Lag Length and Autocorrelation}

The study estimated the optimal number of lags using Akaike information criterion (AIC), Hannan-Quinn information criterion (HQIC) and SBIC criteria, all variables had equal number of lags and were estimated by ordinary least squares. Residuals were tested for autocorrelation using the Lagrange-multiplier test. The null hypothesis was that there was no autocorrelation against the alternative that there was autocorrelation. The model was well specified with the absence of autocorrelation.

\subsection{The Vector Autoregressive Model (VAR)}

VAR model is a multi-equation system where all the variables are treated as endogenous. A system of linear regression equations was derived based on the three study variables with each variable as dependent variable, the righthand side of each equation includes lagged values of all dependent variables considered.

$$
\begin{gathered}
\text { Cancer }_{\mathrm{t}}=\sigma+\sum_{j=1}^{k} \beta_{\mathrm{j}} \text { Cancer }_{\mathrm{t}-\mathrm{j}}+\sum_{j=1}^{k} \Phi_{\mathrm{j}} \operatorname{HIV}_{\mathrm{t}-\mathrm{j}}+\sum_{j=1}^{k} \varphi_{\mathrm{j}} \mathrm{GDP}_{\mathrm{t}-\mathrm{j}}+\varepsilon_{1, \mathrm{t}} \\
\mathrm{HIV}_{\mathrm{t}}=\alpha+\sum_{j=1}^{k} \rho_{\mathrm{j}} \text { Cancer }_{\mathrm{t}-\mathrm{j}}+\sum_{j=1}^{k} \operatorname{jIV}_{\mathrm{t}-\mathrm{j}}+\sum_{j=1}^{k} \varepsilon_{\mathrm{j}} \mathrm{GDP}_{\mathrm{t}-\mathrm{j}}+\varepsilon_{2, \mathrm{t}} \\
\mathrm{GDP}_{\mathrm{t}}=d+\sum_{j=1}^{k} \Phi_{\mathrm{j}} \text { Cancer }_{\mathrm{t}-\mathrm{j}}+\sum_{j=1}^{k} \tau_{\mathrm{j}} \operatorname{HIV}_{\mathrm{t}-\mathrm{j}}+\sum_{j=1}^{k} \eta_{\mathrm{j}} \mathrm{GDP}_{\mathrm{t}-\mathrm{j}}+\varepsilon_{3, \mathrm{t}}
\end{gathered}
$$




\subsection{The Vector Error Correction Model (VECM):}

A vector error correction (VEC) model is a restricted VAR that has co-integration restrictions built into the specification and is designed for use with non-stationary series that are known to be co-integrated. This model is derived as follows:

$$
\begin{aligned}
& \Delta \text { Cancer }_{\mathrm{t}}=\sigma+\sum_{j=1}^{k-1} \beta_{\mathrm{j}} \Delta \text { Cancert }-1_{-1}+\sum_{j=1}^{k-1} \Phi_{\mathrm{j}} \Delta \mathrm{HIV}_{\mathrm{t}-\mathrm{j}}+\sum_{j=1}^{k-1} \varphi_{\mathrm{j}} \Delta \mathrm{GDP}_{\mathrm{t}-\mathrm{j}}+\lambda_{1} \mathrm{ECT}_{\mathrm{t}-1}+\varepsilon_{1, \mathrm{t}} \\
& \Delta \mathrm{HIV}_{\mathrm{t}}=\alpha+\sum_{j=1}^{k-1} \rho_{\mathrm{j}} \Delta \text { Cancert }_{-1}+\sum_{j=1}^{k-1} \quad{ }_{\mathrm{j}} \Delta \mathrm{HIV}_{\mathrm{t}-\mathrm{j}}+\sum_{j=1}^{k-1} \varepsilon_{\mathrm{j}} \Delta \mathrm{GDP}_{\mathrm{t}-\mathrm{j}}+\lambda_{2} \mathrm{ECT}_{\mathrm{t}-1}+\varepsilon_{2, \mathrm{t}} \\
& \Delta \operatorname{GDP}_{\mathrm{t}}=d+\sum_{j=1}^{k-1} \oplus_{\mathrm{j}} \Delta \text { Cancert }_{-1}+\sum_{j=1}^{k-1} \tau_{\mathrm{j}} \Delta \mathrm{HIV}_{\mathrm{t}-\mathrm{j}}+\sum_{j=1}^{k-1} \eta_{\mathrm{j}} \Delta \mathrm{GDP}_{\mathrm{t}-\mathrm{j}}+\lambda_{3} \mathrm{ECT}_{\mathrm{t}-1}+\varepsilon_{3, \mathrm{t}}
\end{aligned}
$$

Where: $\mathrm{k}-1=$ the lag length reduced by $1 ; \beta_{\mathrm{i},}, \Phi_{\mathrm{j},}, \varphi_{\mathrm{j}}, \rho_{\mathrm{j},}, \mathrm{j}, \varepsilon_{\mathrm{j}}$, $\omega_{\mathrm{j}}, \quad \tau_{\mathrm{j}}, \eta_{\mathrm{j}}=$ Short run dynamic coefficients of the model's adjustment long-run equilibrium; $\lambda_{\mathrm{i}}=$ Speed of adjustment parameter with a negative sign with $\mathrm{i}=1,2,3 ; \mathrm{ECT}_{\mathrm{t}-1}=$ the error correction term is the lagged value of the residuals obtained from the co-integrating regression of the dependent variable on the regressors and $\varepsilon_{\mathrm{i}, \mathrm{t}}=$ residuals (stochastic error terms).

\section{Results}

Data was analyzed to identify, describe and explore the relationship between cancer incidence, HIV prevalence and GDP in Uganda.

\subsection{Distribution of Cancer Incidence, HIV Prevalence and GDP}

The graph below shows the distribution of the three variables that is cancer incidence, HIV prevalence and GDP. We can see that there is an upward for cancer incidence and GDP and a down ward trend for HIV prevalence.
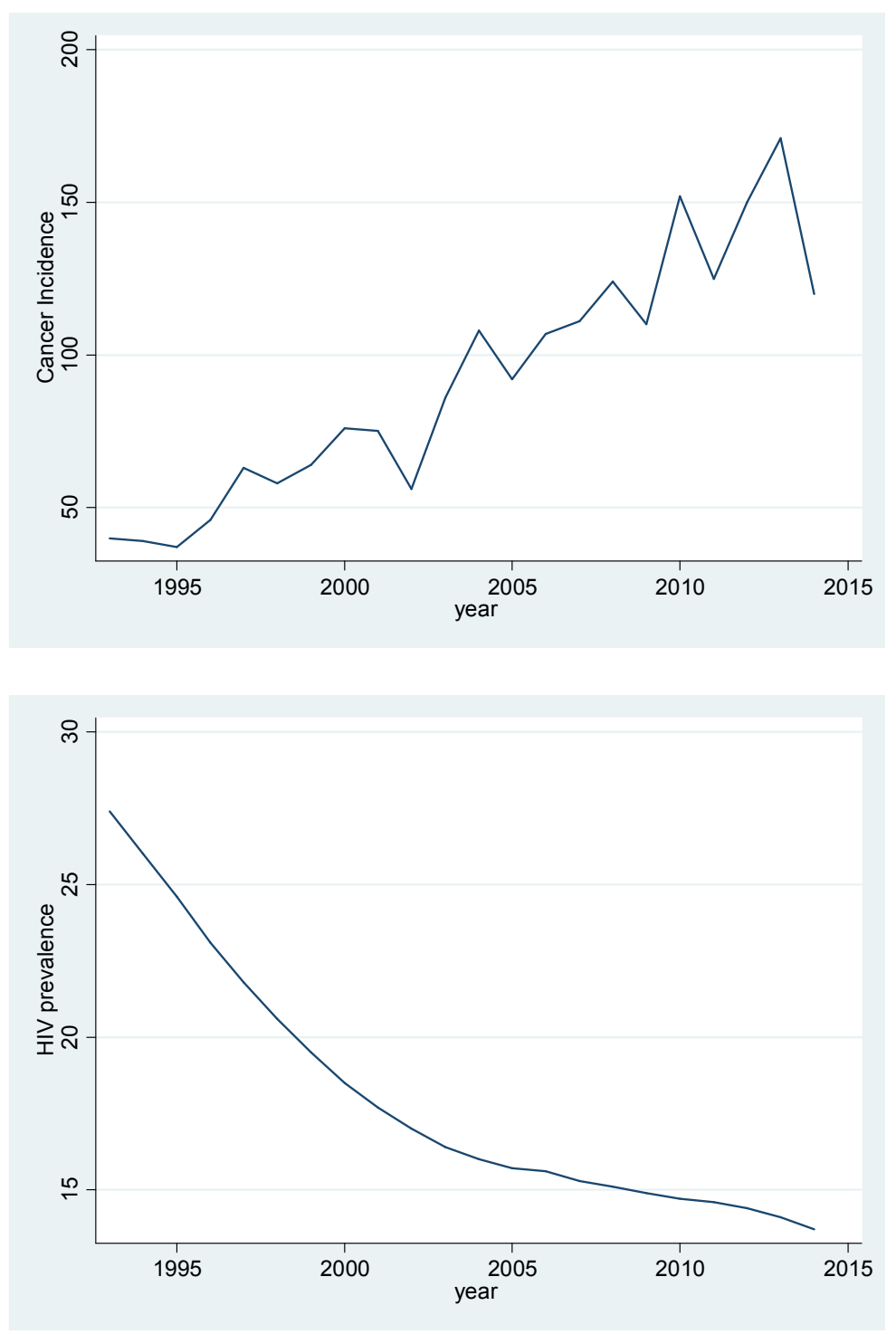


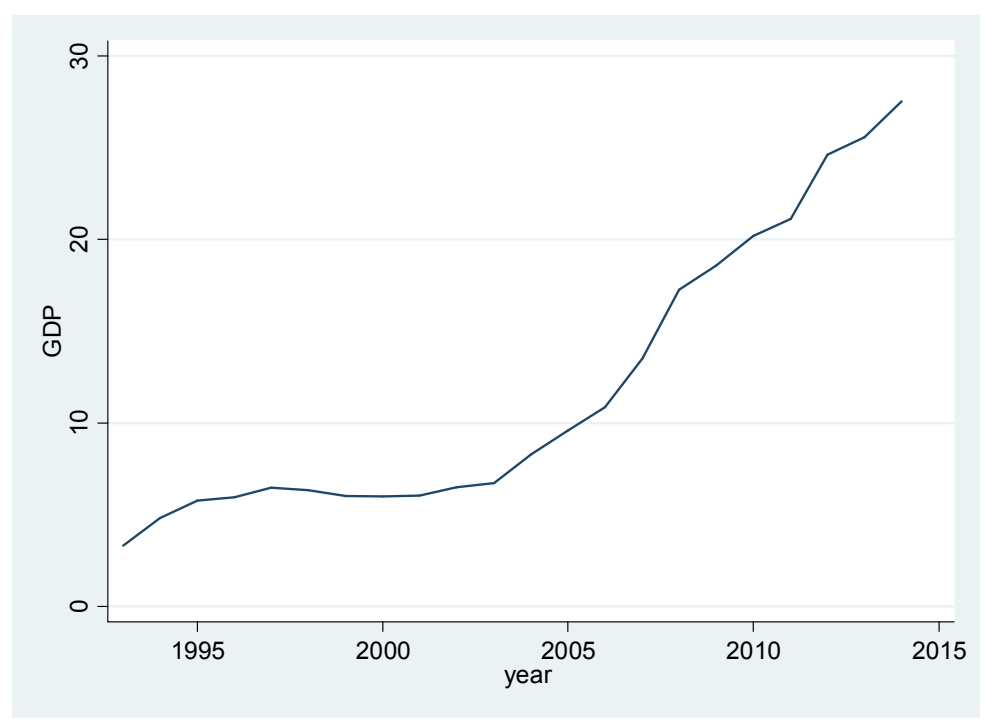

Figure 1. Distribution of cancer incidence, HIV Prevalence and GDP.

From Figure 1: we can see that the variables are nonstationary since there is a trend.

\subsection{Test for Stationarity}

Variables were tested for stationarity using the Augmented Dickey-Fuller test. The null hypothesis was that variables are non-stationary against the alternative that variables are stationary. When the absolute test statistic is greater than the $5 \%$ critical value, we rejected the null hypothesis otherwise we failed to reject the null hypothesis.

Table 1. Non-stationary variables.

\begin{tabular}{llll}
\hline Variables & Test Statistic & $\mathbf{5 \%}$ Critical value & p-value \\
\hline GDP & 1.612 & -3.000 & 0.9979 \\
HIV Prevalence & -2.71 & -3.000 & 0.0723 \\
Incidence of Cancer & -0.778 & -3.000 & 0.8256 \\
\hline
\end{tabular}

From Table 1, we see that the absolute values of the test statistic for all variables, that is, GDP, prevalence of HIV and incidence of cancer are less than the $5 \%$ critical value, hence we fail to reject the null hypothesis and conclude that all the variables are Non-stationary.

Table 2. Stationary Variables after differencing.

\begin{tabular}{llll}
\hline Variables & Test Statistic & $\mathbf{5 \%}$ Critical value & p-value \\
\hline Dgdp & -4.364 & -3.000 & 0.0003 \\
DHIV prevalence & -4.623 & -3.000 & 0.0001 \\
D Incidence cancer & -7.153 & -3.000 & 0.0000 \\
\hline
\end{tabular}

From Table 2, we see that the absolute values of the test statistic for all variables, that is, GDP, prevalence of HIV and incidence of cancer at first differencing are greater than the $5 \%$ critical value, hence we reject the null hypothesis and conclude that all the variables are Stationary at first differencing.

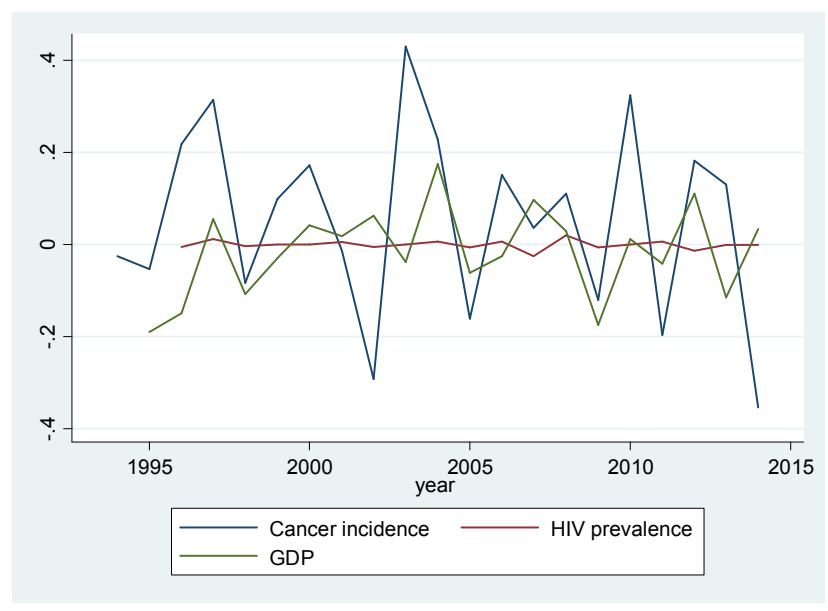

Figure 2. Graph showing stationary variables at first differencing.

Figure 2: shows that Cancer incidence, HIV prevalence and GDP are stationary at first differencing.

\subsection{Co-integration Test of the Variables}

Each of the 10 cancer models were tested for Cointegration using the Johansen test with the null hypothesis being that there was no co-integration against the alternative that there was co-integration.

Table 3. Johansen tests for co-integration.

\begin{tabular}{llll}
\hline Cancer Type & Max Rank & Trace Statistic & 5\% critical Value \\
\hline Breast & 0 & 43.2301 & 29.68 \\
Cervical & 0 & 43.3939 & 29.68 \\
Colon & 0 & 29.2976 & 29.68 \\
Eye & 0 & 41.1769 & 29.68 \\
Hodgkin & 0 & 24.0869 & 29.68 \\
Liver & 0 & 40.0616 & 29.68 \\
Lung & 0 & 35.9854 & 29.68 \\
Non-Hodgkin & 0 & 37.0643 & 29.68 \\
Prostate & 0 & 36.0881 & 29.68 \\
Stomach & 0 & 37.3164 & 29.68 \\
\hline
\end{tabular}


From Table 3, we can see that for breast, cervical, eye, Liver, Lung, Non-Hodgkin, Prostate and stomach cancer the trace statistic was greater than the critical value therefore we rejected the null hypothesis and conclude that there was cointegration hence we ran the VECM model. For Colon cancer and Hodgkin cancer the trace statistic was less than the critical value, therefore we failed to reject the null hypothesis and concluded that there was no co-integration hence we ran the VAR model.

\subsection{Optimal Lag Selection}

The number of lags to be used in the models were determined using the optimal lag selection criteria and Table 4 shows that criteria AIC, HQIC and SBIC all show that 2 lags in our models is optimal.

Table 4. Selection order criteria.

\begin{tabular}{llllllll}
\hline Lag & LL & LR & df & p & FPE & AIC & HQIC \\
\hline 0 & -178.21 & & & & 14875.7 & 18.1209 & 18.1500 \\
1 & -75.432 & 205.55 & 9 & 0.000 & 1.27882 & 8.7432 & 8.8598 \\
2 & -54.554 & 41.756 & 9 & 0.000 & 0.420796 & $7.5554^{*}$ & $7.7595 *$ \\
\hline
\end{tabular}

\subsection{Test for Residual Autocorrelation}

The residual for each variable were tested for autocorrelation using the Lagrange -multiplier test. The null hypothesis was that there was no autocorrelation against the alternative that there was autocorrelation. Since the $p$ values as shown in Table 5 are greater than 0.05 , we failed to reject the null hypothesis and concluded that there was no autocorrelation.

Table 5. Test for residual autocorrelation

\begin{tabular}{lllll}
\hline Cancer Type & Lag & Chi2 & df & Prob>chi2 \\
\hline \multirow{3}{*}{ Breast } & 1 & 7.4813 & 9 & 0.58714 \\
& 2 & 6.8137 & 9 & 0.65651 \\
Cervical & 1 & 14.6635 & 9 & 0.1006 \\
& 2 & 12.1736 & 9 & 0.2037 \\
Colon & 1 & 9.0363 & 9 & 0.43393 \\
& 2 & 7.2786 & 9 & 0.60813 \\
Eye & 1 & 10.6262 & 9 & 0.3022 \\
\hline
\end{tabular}

\begin{tabular}{lllll}
\hline Cancer Type & Lag & Chi2 & df & Prob>chi2 \\
\hline \multirow{3}{*}{ Hodgkin } & 1 & 8.2309 & 9 & 0.51106 \\
& 2 & 4.3709 & 9 & 0.88535 \\
Liver & 1 & 16.2102 & 9 & 0.06262 \\
Lung & 2 & 7.1946 & 9 & 0.616886 \\
& 1 & 4.8843 & 9 & 0.84428 \\
& 2 & 6.8807 & 9 & 0.64953 \\
Non-Hodgkin & 1 & 10.302 & 9 & 0.32659 \\
& 2 & 10.6609 & 9 & 0.29967 \\
Prostate & 1 & 14.6978 & 9 & 0.09958 \\
& 2 & 4.5106 & 9 & 0.87472 \\
Stomach & 1 & 7.2761 & 9 & 0.6084 \\
\hline
\end{tabular}

\subsection{Relationship Between Cancer, GDP and HIV Prevalence in Uganda}

Since there was co-integration for breast, cervical, eye, liver, Lung, Non-Hodgkin, Prostate and stomach cancer, we ran the VECM model to find out the effect of HIV prevalence, GDP on cancer incidence as shown in Table 6.

Table 6. Relationship between cancer, GDP and prevalence of HIV in Uganda.

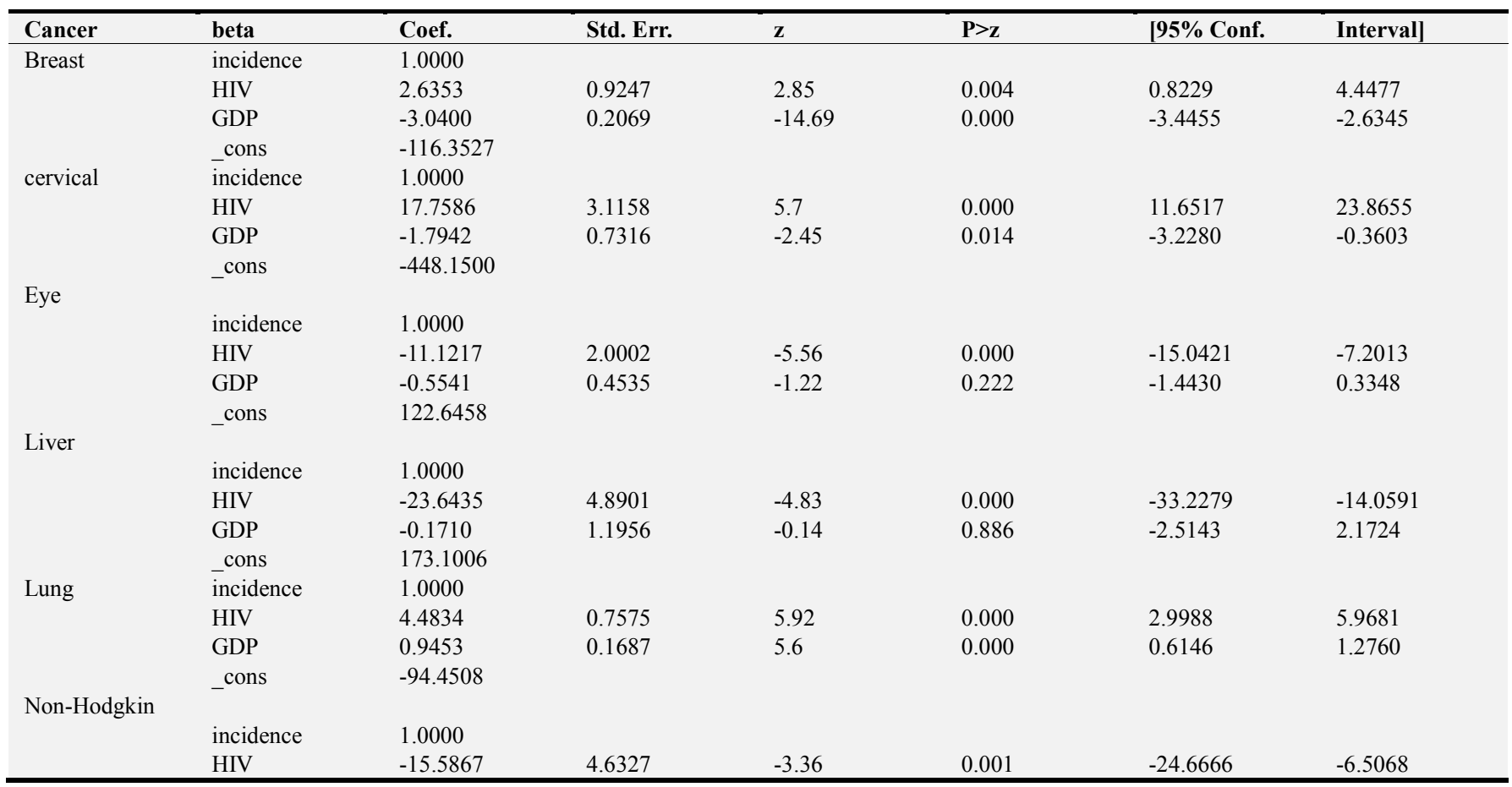




\begin{tabular}{llllllll}
\hline Cancer & beta & Coef. & Std. Err. & $\mathbf{z}$ & P>z & [95\% Conf. & Interval] \\
\hline \multirow{5}{*}{ Prostate } & GDP & -0.7649 & 1.1315 & -0.68 & 0.499 & -2.9825 & 1.4528 \\
& _cons & 62.8046 & & & & \\
& incidence & 1.0000 & & & & \\
& HIV & -34.7054 & 7.7975 & -4.45 & 0.000 & -49.9883 & -19.4225 \\
& GDP & -6.2960 & 1.8304 & -3.44 & 0.001 & -9.8834 & -2.7085 \\
& stomach & 378.2316 & & & & -2.8478 \\
& incidence & 1.0000 & & & & -6.5709 & \\
& HIV & -4.7094 & 0.9498 & -4.96 & 0.000 & -0.4841 & \\
& GDP & -0.0579 & 0.2175 & -0.27 & 0.790 & & \\
\hline
\end{tabular}

From Table 6 we can see that in the long run HIV has a negative significant effect on breast and cervical cancer while GDP has a positive effect on both breast and cervical since the $\mathrm{p}$ values are less than $5 \%$ level of confidence keeping other factors constant. Furthermore, we can see that in the long run GDP has a positive significant effect on eye, NonHodgkin and prostate cancer since the p-values are less than $5 \%$. However, in the long run GDP has a negative significant effect on Lung cancer at 5\% level of confidence keeping other factors constant. HIV has a long run positive significant relationship on eye, liver, Non-Hodgkin, Prostate and Stomach cancer at 5\% level of confidence keeping other factors constant.

\subsection{Relationship Between Colon Cancer, GDP and Prevalence of HIV in Uganda}

The Table below shows the relationship between incidence of colon cancer, Lagged GDP and lagged prevalence of HIV in Uganda after running a vector autoregressive model.

Table 7. Relationship between Lagged incidence of Colon cancer, lagged GDP and lagged prevalence of HIV in Uganda.

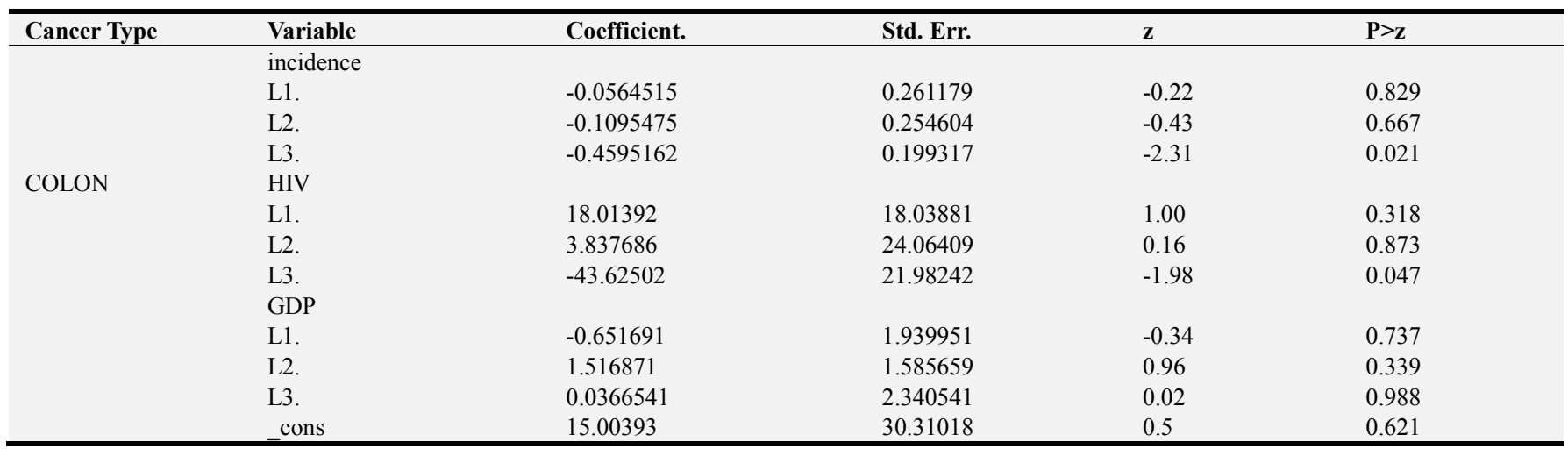

From Table 7, the third lag of HIV prevalence has a negative significant relationship with incidence of Colon cancer since the p-values is less than 0.05 .

\section{Discussion}

From Table 6, there is a long run negative significant relationship between HIV prevalence and incidence of breast cancer since the $p$ value is less than 0.05 . Furthermore, there is also a long run positive significant relationship between GDP and breast cancer. This is also noted by [15] that wealthier countries tended to have higher breast cancer incidence rate with the age-standardized incidence rate in more developed countries two times as high as in less developed countries. In China, positive correlation between breast cancer mortality rate and GDP was found. In addition [17] states that as longevity improves in HIV-positive patients with the use of HAART, their risk for developing breast cancer continues to increase, similar to the general population.

There is a long run negative significant relationship between HIV prevalence and incidence of cervical cancer since the $p$ value is less than 0.05 . Furthermore, there is a long run positive significant relationship between GDP and cervical cancer since the p-value is less than 0.05 . This is in line with [16] who said that HIV-infected women as a special population, are at increased risk for cervical cancer. Overall risk of co-morbid conditions will increase with aging of the HIV-positive population. In addition (Polesel et al., 2008) state that cervical cancer mortality is associated with povertyrelated factors, including lack of formal education, unemployment, low socio-economic level, rural residence and insufficient access to healthcare.

From Table 7 there is a significant relationship between all lagged HIV prevalence and incidence of colon cancer since the $\mathrm{p}$ value is less than 0.05 . Furthermore, there is also a significant relationship between GDP and colon cancer since the p-value is less than 0.05. Also, both HIV and GDP jointly cause colon cancer. This is in line with [9] who stated that the incidence of many types of non-AIDSdefining cancer such as cancer of the colon was higher among HIV-infected persons than among the general 
population. A Study by [15] notes that Colon cancer, nevertheless, showed a positive association, with high-GDP Per Capita areas having the highest age standardized incidence rate (ASIR). Colon cancer showed a positive association with GDP level.

There is a long run positive significant relationship between HIV prevalence and cancer of the eye since the $p$ value is less than 0.05 . This is in line with [15] who stated that Squamous cell carcinoma of the conjunctiva is associated with the human immunodeficiency virus and is thus a marker for the disease in Benin City, Nigeria.

There is a long run positive significant relationship of HIV prevalence, GDP and Liver cancer since the $\mathrm{p}$ value is less than 0.05 . The article by [10] observed that people coinfected with HIV and viral hepatitis tend to experience more rapid liver disease progression and respond less well to treatment than those with hepatitis B virus (HBV) or hepatitis $\mathrm{C}$ virus (HCV) alone. As antiretroviral therapy has reduced mortality due to AIDS, liver disease including hepatocellular carcinoma has become a growing cause of death among people with HIV.

There is a long run positive significant relationship between HIV prevalence and Non-Hodgkin cancer since the $\mathrm{p}$ value is less than 0.05 . Furthermore, there is also a long run positive significant relationship between GDP and NonHodgkin cancer since the $\mathrm{p}$-value is less than 0.05 . The researchers [19] noted that, the incidence of NHL declined gradually in patients initiating HAART and even at persistent severe immune deficiency, HAART protects against NHL. The natural history including the clinical prognosis of NHL has not changed after the introduction of HAART. In the era of HAART, patients at highest risk of developing NHL are those who did not respond adequately to HAART, that is, remained at low CD4 cell count and insufficiently suppressed viral replication.

There is a long run positive significant relationship between HIV prevalence and Prostate cancer since the $p$ value is less than 0.05 . Furthermore, there is also a long run positive significant relationship between GDP and Prostate cancer since the p-value is less than 0.05 . In reference with [16] states that Prostate cancer is a common malignancy in HIV-positive men. With improved therapies for HIV and increasing survival, the importance for screening and treating prostate cancer is increasing. Furthermore in a study about comparison of cancer incidence and mortality in three GDP per capita levels in china $[15,20]$ stated that Prostate cancer had the highest age-standardized incidence rate (ASIR) in all cancer types for men in more developed areas and was the second most common cancer for men worldwide.

There is a long run positive significant relationship between HIV prevalence and stomach cancer since the $p$ value is less than 0.05 . Furthermore, GDP had a long run positive significant relationship with stomach cancer. This is in line with [18] who said that overall, people with AIDS are at higher risk for stomach and esophageal cancer than the general population. That this could be due to more frequent use of tobacco and alcohol, or perhaps obesity, among people with AIDS.

There is a long run negative significant relationship between HIV prevalence and Lung cancer since the $p$ value is less than 0.05. Furthermore, GDP had a long run negative significant relationship with Lung cancer. This is in line with [19] who said that Lung cancer is a leading non-AIDS defining cancer (NADC) and is the most frequent cause of cancer deaths in HIV infected persons. This is largely related to higher smoking rates among HIV infected persons, but also due to independent, HIV-related increased lung cancer risk. With improved HIV disease control, larger numbers of patients are surviving long enough to develop and die from lung cancer. Further still [16] said that lung cancer was also the leading cause of cancer death, regardless of gender and gross domestic product per capita (GDPPC) level. Negative associations with GDPPC level were found for the age-standardized incidence rate (ASIRs) of lung cancer.

\section{Conclusions}

The purpose of this research was to determine the association of cancer incidence, HIV prevalence and GDP in Uganda. Non-AIDS defining cancers, that is, stomach, eye, liver cancer and prostate cancer had a long run positive significant relationship with HIV prevalence while colon, lung and breast cancer had a negative significant relationship with HIV prevalence. These cancers (breast cancer and prostate) had a positive significant relationship with Gross domestic product while cancer of the lung had a negative significant relationship with gross domestic product in Uganda.

AIDS defining cancers, that is, Non-Hodgkin cancer had a long run positive significant relationship with HIV prevalence while cervical cancer had a negative significant relationship with HIV prevalence. These cancers (NonHodgkin and cervical cancer) had a positive significant relationship with Gross domestic product in Uganda.

In line with the findings presented the following recommendations are provided towards reducing the incidence of cancer and prevalence of HIV in Uganda; (i) Government should focus on reducing the prevalence of HIV in the population since it has been observed that there is a relationship between HIV and cancer, (ii) Government should focus on sensitizing and making available cancer screening centers in both rural and urban areas for HIV infected patients for NON-AIDS defining cancers. Further research that can been done include finding out cancer in HIV-positive patients to help guide preventive care guidelines for screening and diagnosis of cancer.

\section{Acknowledgements}

Many thanks to Kampala Cancer Registry, Department of Pathology, College of Health Sciences, Makerere University for providing us with cancer data. 


\section{References}

[1] American Cancer Society. (2019). Cancer Facts \& Figures 2009. Atlanta: American Cancer Society.

[2] UNAIDS. Global AIDS update 2016 http://www.unaids.org/sites/default/files/media_asset/globalAIDS-update-2016_en.pdf Accessed 8 February 2020.

[3] Marie-Josephe Horner, Steady Chasimpha, Adrian Spoerri, Jessie Edwards, (2019). High Cancer Burden among Antiretroviral Therapy users in Malawi: A record linkage study of observational Human Immunodeficiency Virus Cohorts and Cancer Registry Data. Clin Infect Dis., 69 (5): 829-835.

[4] Hernandez-Ramirez RU, Shiels MS, Dubrow R, Engels EA. Cancer risk in HIV-infected people in the USA from 1996 to 2012: a population-based, registry-linkage study. Lancet HIV 2017; 4: e495-e504.

[5] World Health Organization. (2017). Facts About Cancer in Uganda. Retrieved from http://health.go.ug/sites/default/files/Cancer Booklet.pdf

[6] Chen W, Zheng R, Zhang S, et al. Cancer incidence and mortality in China, 2013. Cancer Lett. 2017; 401: 63-71. doi: 10.1016/j.canlet.2017.04.024.

[7] Chen SL, Wang SC, Ho CJ, et al. Prostate cancer mortality-toincidence ratios are associated with cancer care disparities in 35 countries. Sci Rep. 2017; 7: 40003. doi: 10.1038/srep40003.

[8] Zhixun Yang, Rongshou Zeng, Siwei Zhang, Hongmei Zeng, Changfa Xia, Li Wang, Yanhong Wang and Wanging Chen (2017). Comparison of Cancer incidence and mortality in three GDP per capita levels in China, 2013, Chinese Journal of Cancer Research, 29 (5): 385-394.

[9] Jemal, A., Bray, F., Forman, D., O’Brien, M., Ferlay, J., Center, M., \& Parkin, D. M. (2012). Cancer burden in Africa and opportunities for prevention. Cancer, 118 (18), 43724384. https://doi.org/10.1002/cncr.27410

[10] Juan B. (2013). HIV \&amp; AIDS Information : Liver cancer often diagnosed late with poor survival in people with HIV. Retrieved September 6, 2018, from http://www.aidsmap.com/Liver- cancer-often-diagnosed-latewith-poor-survival-in-people-with-HIV/page/2771705/
[11] IMF. (2017). GDP by Country | Statistics from IMF, 19802021 - Hawaii Open Data. Retrieved. September 15, 2017, from http://hawaii.knoema.com/tbocwag/gdp-by-countrystatistics-from-imf-1980-2021/country=Uganda

[12] Zou, X. (2018). VECM Model Analysis of Carbon Emissions, GDP, and International Crude Oil Prices. Discrete Dynamics in Nature and Society, 2018, 1-11.

[13] Sloan DJ, van Oosterhout JJ, Malisita K, et al. (2013) Evidence of improving antiretroviral therapy treatment delays: an analysis of eight years of programmatic outcomes in Blantyre, Malawi. BMC Public Health 2013.

[14] UNAIDS (2017), UNAIDS DATA 2017 Publication. https://www.unaids.org/en/resources/documents/2017/2017_d ata_book.

[15] Yang, Z., Zheng, R., Zhang, S., Zeng, H., Xia, C., Li, H., ... Chen, W. (2017). Comparison of cancer incidence and mortality in three GDP per capita levels in China, 2013. Chinese Journal of Cancer Research = Chung-Kuo Yen Cheng Yen Chiu, 29 (5), 385-394.

[16] Ghebre, R. G., Grover, S., Xu, M. J., Chuang, L. T., \& Simonds, H. (2017). Cervical cancer control in HIV-infected women: Past, present and future. Gynecologic Oncology Reports, 21, 101-108. https://doi.org/10.1016/j.gore.2017.07.009

[17] Ferlay, J., Shin, H.-R., Bray, F., Forman, D., Mathers, C., \& Parkin, D. M. (2010). Estimates of worldwide burden of cancer in 2008: GLOBOCAN 2008. International Journal of $\begin{array}{llll}\text { Cancer, } & 127 & \text { (12), }\end{array}$ https://doi.org/10.1002/ijc.25516

[18] Wabinga, H. R., Nambooze, S., Amulen, P. M., Okello, C., Mbus, L., \& Parkin, D. M. (2014). Trends in the incidence of cancer in Kampala, Uganda 1991-2010. International Journal of Cancer, 135 (2), 432-439. https://doi.org/10.1002/ijc.28661

[19] Sigel, K., Makinson, A., \& Thaler, J. (2017). Lung cancer in persons with HIV. Current Opinion in HIV and AIDS, 12 (1), 31-38 https://doi.org/10.1097/COH.0000000000000326

[20] Polesel, J., Clifford, G. M., Rickenbach, M., Dal Maso, L., Battegay, M., Bouchardy, C., Franceschi, S. (2008). NonHodgkin lymphoma incidence in the Swiss HIV Cohort Study before and after highly active antiretroviral therapy. AIDS, 22 (2), 301-306. 